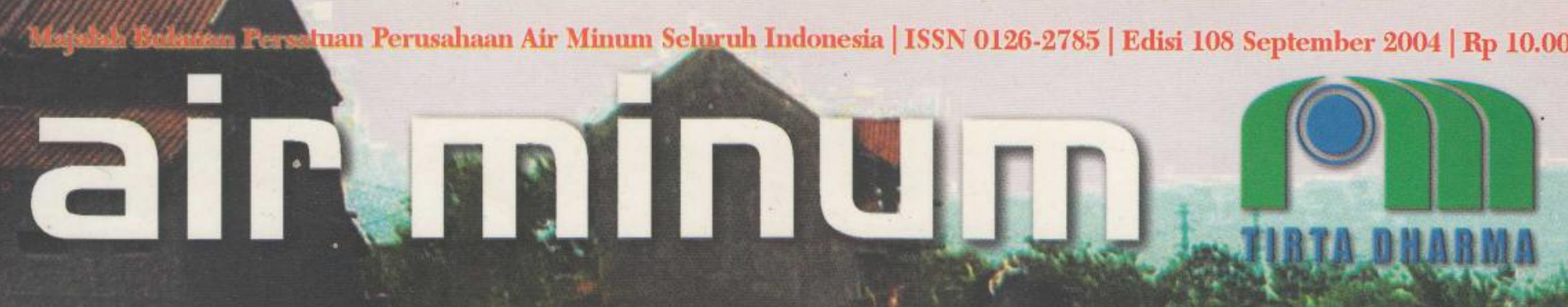

PDAM Demea

sSmall is

Bea

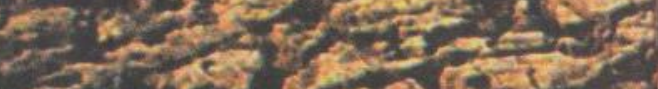

T) 32,2 .
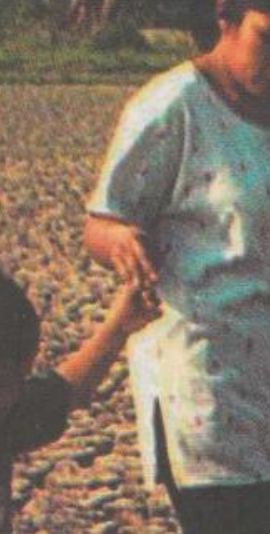

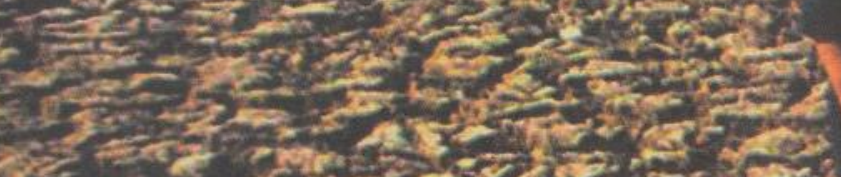

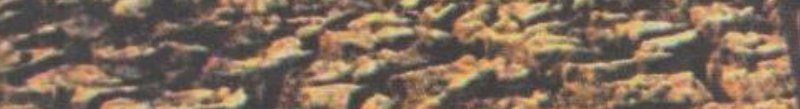

xast

(4)

W. Sxt (2)

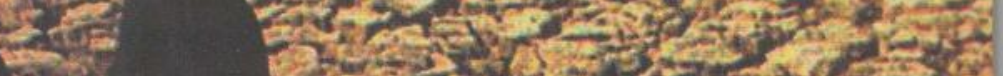

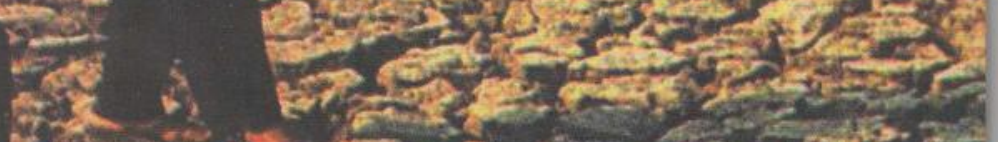
(1)

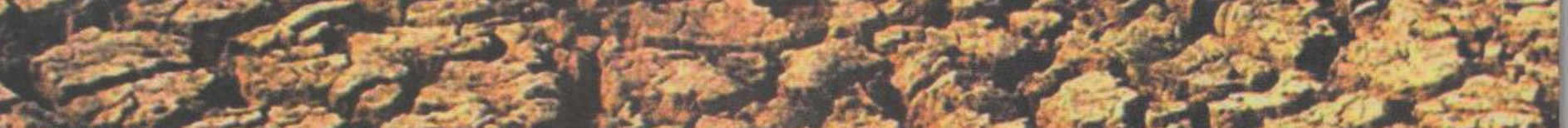
2.

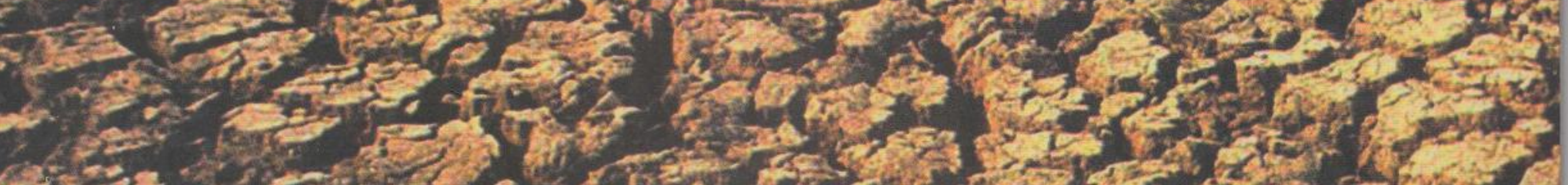

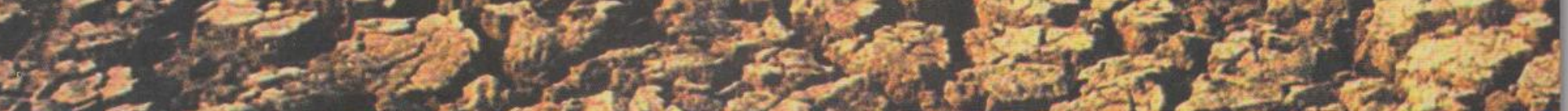

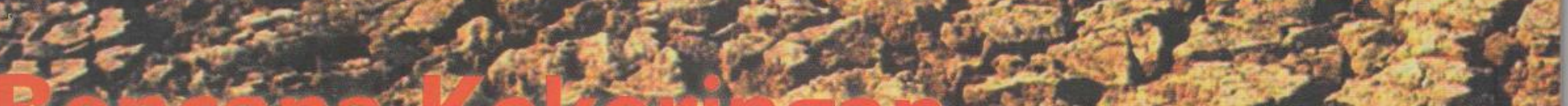

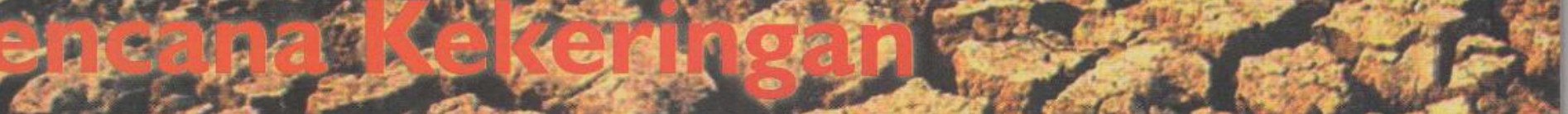

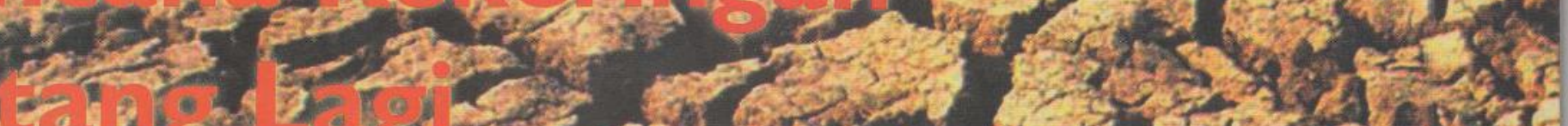
tar

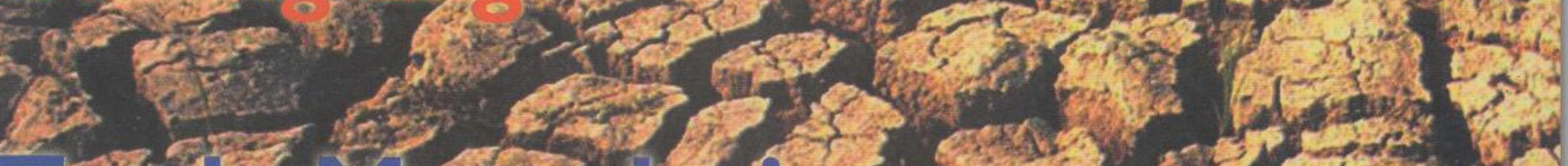
ahda vata dares 3 , U sa ntaravatern 2004 .

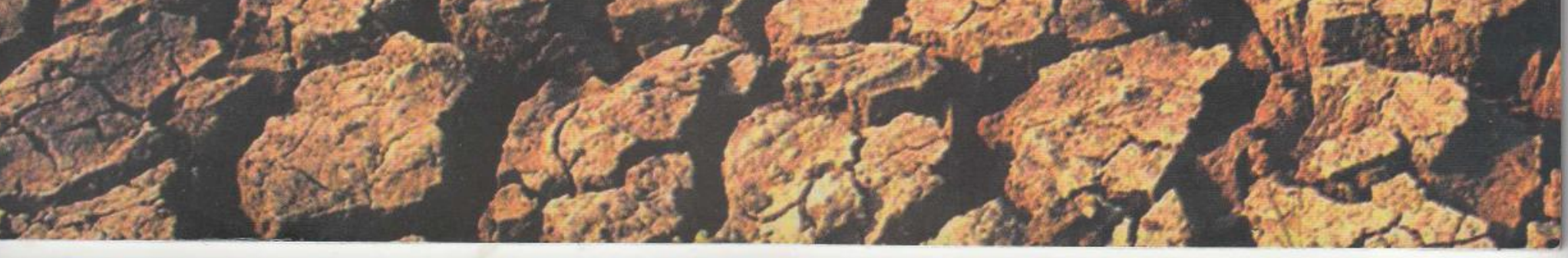


hiasan atau untuk keperluan bersuci (wudhu) bagi kaum muslim.

Pada masa silam di mancanegara, nilai-nilai spiritual atau pendewaan air telah luas dikenal. Di Prancis, di dekat Sungai Seine, ada kuil suci untuk Dewa Sequana. Sungai Marne asal-usul namanya dari Matrona yang artinya Dewi Ibu. Cikal nama Sungai Thames di Inggris adalah Tamesa atau Tamesis yang terkait dengan makna ketuhanan. Sungai Nil di Mesir tak lepas dari Fir'aun dan Nabi Musa. Adapun Sungai Amazon di hutan belantara Brasil, Amerika Latin dihuni oleh suku pemulia dewa-dewi.

Tersebut, yakni pendewaan atas air adalah upaya manusia untuk menyelamatkan hidupnya yang benarbenar bergantung pada air. Dan air, kita tahu, bergantung pada hutan. Tradisi ujung ladang masyarakat Melayu di Sumatra Utara misalnya, senantiasa berwawasan lingkungan kalau membuka hutan. Meski menebang dan membabat pohon, selalu ada vegetasi pelindung yang selingkung dengan sentra budidayanya.

Suku Dayak di Kalimantan juga punya tradisi Nyaang. Mereka terbiasa membuat lajur isolasi pada ladang atau ketika pembabatan hutan untuk melokalisir jika terjadi kebakaran sehingga air pun terselamatkan. Selanjutnya adalah awig-awig orang Bali yang melarang menebang pohon (bunut atau beringin) dan biasanya dibuatkan tempat untuk menaruh sesajen. Kemudian, tradisi sasi di Saparua, Maluku yang berlaku di daratan atau di lautan terhadap komoditas yang tidak boleh diambil atau dieksploitasi untuk waktu terbatas.

Itu semua adalah fenomena kearifan tradisional yang "mendewakan" air demi terciptanya keberlangsungan (sustainability) air dan kehidupan manusia.

Makanya sangat aneh kalau kita yang "mendewakan" air tetapi malah krisis air. Sanitasi kita banyak yang buruk bin kumuh. Silakan simak. Sekarang ini, paling sedikit ada dua miliar orang tidak memiliki akses air bersih dan 3,1 miliar orang tidak memiliki fasilitas sanitasi yang sehat. The World Bank menulis: ada 900 juta orang di 100 negara menghadapi masalah desertifikasi (penggurunan hutan) lantaran interaksi kompleks antara faktor fisika, biologi, politik, sosial, budaya dan ekonomi dengan kerugian 42,3 miliar dollar AS setahun. Ini bakal berdampak keras pada air bersih dan sanitasi untuk mencapai cita-cita Millenium Development Goals 2015. Jangan-jangan hal ini sekadar utopia belaka. Tapi sudahlah, kita ikhtiarkan dulu untuk mencapainya.

\section{Mendewasakan PDAM}

Di tatar Sunda, Jawa Barat ada katakata hikmah seperti ini: leuweung ruksak - cai beak-manusa balangsak, no forest - no water - no future. Terjemahan bebasnya: hilang hutan - hilang air hilang masa depan. Begitu tulis Prof. Dr. Ir. Mubiar Purwasasmita dalam sambutannya di buku PDAM Bangkrut? Awas Perang Air. Artinya: tiada hutan, tiadalah air, habislah PDAM. Tamat pula riwayat kita. Dalam arti sebaliknya, jika ada hutan, otomatis ada air dan PDAM bisa eksis. Namun fakta berkata lain. Hanya 9\% dari 300-an PDAM dalam kondisi sehat. Lainnya masih sakit. Bahkan ada yang masuk ke unit gawat darurat. Terancam bangkrut. Janganjangan hakikatnya sudah bangkrut tetapi tidak kentara. Tidak kelihatan.

Kasus di atas tentu bertentangan dengan prinsip "mendewakan" air. Bahwa air "disembah" sudah kita ketahui. Bahwa hutan menjadi ladang air, sudah kita pahami. Maka sepantasnyalah PDAM makin maju dan untung. Tapi apa yang terjadi? Mayoritas PDAM ternyata masih kanak-kanak lantaran belum mandiri. Banyak yang tak mampu mengongkosi dirinya dan masih harus disapih oleh pemerintah daerah.

Padahal fenomena historis pendewaan atas air adalah peluang bagus bagi PDAM untuk maju dengan menjual air yang dibutuhkan manusia. Ketika air minum kemasan (amik) dan air minum kemasan ulang (amiku) gencar menyerbu, PDAM tetap masih berpeluang bersaing. Malah ada PDAM yang sudah merilis produk amik. Kalau Begitu apa masalahnya? Pasti ada sesuatu yang salah di PDAM dan mesti segera diperbaiki. Mesti ada reformasi di pabrik air ini. Salah satu caranya adalah pola piramid.

Ilustrasinya tampak pada gambar. Demi mencapai maksud di atas formula piramid dapat dijadikan alat. Dalam mengembangkan PDAM, kita tak bisa lepas dari reformasi kekaryaan $\mathrm{P}$ (pegawai), reformasi rekayasa $\mathrm{D}$ (desain), A (area servis), M (manajemen) dan K (konsumen/pelanggan). Termasuk menata empat dinding piramid yang mewakili Trilogi AIR: A (aman), I (isi), dan R (rutin/kontinyu) serta $\mathrm{T}$ (tarif). Adapun $\mathrm{L}$ adalah lingkungan piramid, ruang bagi pemerintah pusat dan daerah serta DPR(D) sebagai pembuat peraturan yang mengacu ke pasal 33 UUD 1945.

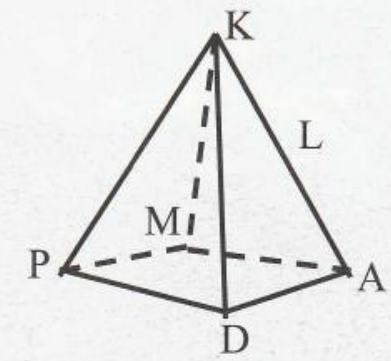
Piramid PDAM
P : pegawai/pekerja;
D : desain;
A : area servis;
M : manajemen;
$\mathrm{K}$ : konsumen
$\mathrm{L}$ : lingkungan (DPR/D, pemerintah pusat/daerah)

Mendewasakan PDAM dengan cara membangun piramid PDAM dan berkehendak menjalani swakritik. Introspeksi diri dengan mereparasi SDM-nya (pegawai), desain instalasidistribusinya, meluaskan area servisnya dan menata manajemennya. Sudah waktunya PDAM berubah dan mematut dirinya. Jangan seperti katak dalam tempurung; menjadi jago kandang. Rintislah orientasi global. Tirulah perusahaan air swasta yang sudah maju. Pasti bisa. Tentu harus didukung total oleh insan-insan PDAM sendiri.

Ketika orang mendewakan air, bergantung pada air, kita pun bisa mendewasakan PDAM agar bangkit dan mandiri. Meraih laba yang signifikan. Kuat berdikari. 